\title{
A INSTITUCIONALIZAÇÃO DO TRABALHO DO AGENTE COMUNITÁRIO DE SAÚDE
}

\author{
THE INSTITUTIONALIZATION OF THE WORK OF THE COMMUNITY HEALTH AGENT
}

\author{
Agleildes Arichele Leal de Queirós ${ }^{1}$ \\ Luci Praciano Lima ${ }^{2}$
}

Resumo O objetivo desta pesquisa é analisar a prática social do trabalho do agente comunitário de saúde (ACS) no Recife, Pernambuco, Brasil. Para tanto, adotou-se uma abordagem qualitativa, cuja ferramenta teórico-metodológica está alicerçada no materialismo histórico e dialético. O ACS é singular na sua conformação, pois tem no seu contexto de trabalho e de moradia um importante recorte de classe social. Apesar da institucionalização do trabalho do ACS, ele mantém na sua prática referências forjadas na sua atuação popular e comunitária. Destacamos que a institucionalização do trabalho do ACS, por si só, é um processo contraditório e conflituoso do ponto de vista da política institucional, já que a prática desenvolvida por ele incorpora saberes e práticas populares que podem gerar tensões. Ao mesmo tempo, é importante lembrar que o território onde vive e atua o ACS exerce influência na produção do seu trabalho.

Palavras-chave trabalho em saúde; saúde da família; agente comunitário de saúde.
Abstract The purpose of this research is to analyze social practices in the work of community health agents (ACSs) in the city of Recife, state of Pernambuco, Brazil. Accordingly, a qualitative approach was adopted, whose theoretical-methodological aspects were founded on historical and dialectic materialism. ACSs have a unique role, because they deal with an important cross-section of social classes in their work and living spaces. Despite the institutionalization of their work, it still contains references forged during their work with the community and the population at large. We emphasize that the institutionalization of the work of ACSs, in and of itself, is a contradictory and conflicting process from the standpoint of institutional policy, since the practice developed by them incorporates popular wisdom and practices that may create tensions. At the same time, it is important to remember that the territory where the ACSs live and operate exerts an influence on their professional production.

Keywords health work; family health; community health agent. 


\title{
Introdução
}

\author{
Os homens fazem a sua própria história, mas \\ não a fazem como querem, não sobre circuns- \\ tâncias de sua escolha e sim com aquelas com \\ que se defrontam diretamente, ligadas e trans- \\ mitidas pelo passado (Marx, 1978, p. 15).
}

Compreendemos que as mudanças no mundo do trabalho e a interrogação sobre a sua centralidade na sociedade contemporânea têm provocado incansáveis debates e reflexões. Marx (2006) assinala que o trabalho está presente na relação do homem com a natureza desde tempos remotos, consistindo num processo em que o ser humano - com sua própria ação - impulsiona, regula e controla seu intercâmbio material com a natureza. Para Nakatani (2001, p. 3) "foi através do trabalho que se desenvolveram as demais funções e comportamentos humanos", uma vez que a ação realizada pelo homem é previamente projetada na consciência e, ao ser objetivada, é transformadora da natureza e do próprio homem.

Segundo Lessa (1999), é na esfera da reprodução social que são geradas novas necessidades e possibilidades, que darão origem a novas relações sociais. Tais relações darão origem a novas relações sociais, que se organizam sob a forma de complexos sociais. ${ }^{3}$ Assim, as necessidades sociais, no caso, as de saúde, podem ser definidas como carências individuais, que mudam de acordo com as classes sociais a que pertencem.

(...) o trabalho é compreendido como processo dirigido por determinado projeto que tem como base o atendimento de determinadas necessidades sociais. Considerando-se que em nossa sociedade as relações sociais resultam da luta entre as classes sociais, compreende-se que existe uma disputa permanente pela direção desse processo. A produção da saúde apresenta-se e se constitui como expressão histórica dessas tensões e disputas, das quais derivam duas concepções de saúde distintas: a que a concebe como mercadoria, como reprodutora da mercadoria força de trabalho e como mecanismo de distensionamento/conformação social; e outra, para a qual a saúde é considerada um direito que deve ser garantido a todos os seres humanos, não se restringindo à ausência de doença, e sim dizendo respeito à garantia de condições de vida plena em todas as suas dimensões (Lopes, Durão e Carvalho, 2011, p. 163).

Para Pires (2000) o trabalho em saúde é parte do setor de serviços, localizado num patamar de produção não material, que adquire sentido de completude no ato de sua realização. Ou seja, não tem como resultado um produto material, “já que o produto é indissociável do processo que o produz; 
é a própria realização da atividade" (Pires, 2000, p. 85). Rodrigues e Araújo (2003, p. 2) reiteram que "são serviços produzidos pelo encontro entre quem produz e quem recebe, ou seja, a produção é singular e se dá no próprio ato".

O Sistema Único de Saúde (SUS) tem na universalidade e na integralidade princípios que mostram a intencionalidade de atender às necessidades de todos e de apreendê-las de forma ampliada. Nesse cenário, a atenção primária ganha importante espaço e estabelece como estratégia central a inserção de um novo trabalhador, o agente comunitário de saúde (ACS).

Os primeiros ACS surgiram em várias comunidades, de diversos municípios do país, entre as décadas de 1960 e 1970, como resgatam os estudos de Silva e Dalmaso (2002), Doimo e Rodrigues (2003), Morosini, Corbo e Guimarães (2007) e Queirós (2008). Mas foi somente na década de 1990 que ocorreu sua inserção em nível nacional: em 1991, com o Programa Nacional de Agente Comunitário de Saúde (PNACS), que já em 1992 tornou-se Programa de Agente Comunitário de Saúde (Pacs); a partir de 1994, surge o Programa Saúde da Família (PSF), que criou equipes multiprofissionais e se tornou a principal estratégia de reorganização do modelo de atenção à saúde no Brasil.

A institucionalização dos agentes de saúde tem início na década de 1970, em diversas regiões do país, por meio da incorporação ao sistema de saúde de trabalhadores voluntários ou de praticantes leigos interessados em contribuir com ações sociais para ajudar a população, principalmente as camadas mais pobres, que não contribuíam para a previdência social e que, portanto, não tinham acesso aos serviços públicos de saúde. Alguns voluntários eram militantes políticos e/ou lideranças locais vinculadas a instituições religiosas que prestavam atendimento na área da saúde, tais como a Pastoral da Criança e as dioceses. Ao menos no caso de Pernambuco, a origem desses agentes está relacionada à luta contra a pobreza e por melhores condições de vida, em um contexto de resistência ao autoritarismo do regime militar que teve em Dom Hélder Câmara uma de suas principais lideranças (Chinelli, Lacerda e Vieira, 2011, p. 66).

No Recife, o surgimento do ACS ocorreu em meados da década de 1960, como resistência e resposta popular diante da grande repressão da ditadura e, também, às precárias condições de saúde da população. O ACS, no Recife, confunde-se com a própria história do Movimento Popular de Saúde (Mops), como será discutido no transcorrer deste artigo.

O ACS é hoje a maior categoria de trabalhadores do SUS, chegando a 246.130 agentes em todo o país (Brasil, 2011). Assim, os ACS vêm construindo sua história profissional, definindo frentes de mobilização no sentido do seu reconhecimento, inserção, regulamentação e valorização. Neste momento, 
estratégias como o PSF e a inserção do ACS como trabalhador do SUS tornam-se políticas estruturantes para a saúde pública do país. O estudo em questão defende que há uma inter-relação entre a acumulação do capital, as complexas lutas de classe e as formas de organização política do Estado e da sociedade, e que esta inter-relação perpassa a institucionalização do ACS.

A produção de cuidado proposta num contexto social tão complexo como o comunitário suscita a necessidade de recrutar trabalhadores com domínio de saberes e práticas diferentes das produzidas pelas instituições de educação que formam para o setor saúde. É fundamental que o ACS consiga desenvolver estratégias que partam da concepção e da práxis popular. Neste sentido, é relevante a análise sobre o ACS, partindo do pressuposto de que ele é, dentro do campo da saúde, um trabalhador estratégico para o estudo das novas morfologias do trabalho em serviço e das mediações dessa categoria diante das lutas sociais. Essas práticas e saberes têm, portanto, implicações políticas e encerram uma luta entre grupos e classes sociais que conformam essas instituições e que estão inseridos em um bloco histórico (Luz, 1981).

Compreendemos, ainda, que o cenário da institucionalização do ACS constitui-se através de relações complexas de uma totalidade social estruturada historicamente. Com o propósito de elucidar a produção social desse trabalhador, recorremos às categorias empregadas por Serra (1986) - Estado, instituição e prática profissional - para analisar os depoimentos colhidos.

\section{Caminhos metodológicos}

\section{O caminho percorrido}

Esta é uma pesquisa qualitativa, cujo arranjo metodológico e analítico está implicado com: o pesquisador; o paradigma e a perspectiva teórica; a estratégia de pesquisa; o método de coleta e análise; e a 'arte', as práticas e a política da interpretação e da apresentação (Denzin e Lincoln, 2006). O objeto do estudo foi analisado à luz do materialismo histórico e dialético. É importante apreender que dialética é posição, método e práxis.

Na perspectiva materialista histórica, o método está vinculado a uma concepção de realidade, de mundo e de vida no seu conjunto. A questão da postura, nesse sentido, antecede ao método. Este se constitui numa espécie de mediação no processo de apreender, revelar e expor a estruturação, o desenvolvimento e transformação dos fenômenos sociais (Frigotto, 1991, p. 77).

A dialética é um atributo da realidade, isso significa que ela tem ponto de partida e que é preciso buscar a superação das impressões iniciais e 
ressignificá-las a partir do concreto. Frigotto (1991, p. 31) acredita que "é preciso, então, não confundir o movimento do real com suas contradições, conflitos, antagonismos, com o movimento do pensamento no esforço de apreender esse movimento da forma mais completa possível". Assim, compreende-se que "o conhecimento da realidade histórica é um processo de apropriação teórica - isto é, de crítica, interpretação e avaliação dos fatos processo em que a atividade do homem, do cientista, é condição necessária ao conhecimento objetivo dos fatos" (Kosik, 1976, p. 84).

Utilizamos a adaptação do método feita por Gadotti (2004). Este autor propõe a organização do método dialético em duas partes: a fase de investigação da pesquisa, que busca se apropriar da realidade estudada, através de uma análise que evidencie as relações internas; e a fase de exposição, que entende a reconstituição, a síntese do objeto ou fenômeno estudado, como um processo inverso, oposto ao primeiro. Por meio do método dialético, o fenômeno ou objeto estudado é apresentado ao leitor de forma que ele o apreenda em sua totalidade. Para isso são necessárias aproximações sucessivas e cada vez mais abrangentes do objeto.

Este estudo caracteriza-se por processos de investigação e de exposição. A fase de investigação diz respeito ao recolhimento do material. Nessa fase são abordados os pressupostos teóricos no qual o trabalho se fundamenta. A reflexão sobre a realidade nos oferece uma base potente para compreender o contexto sociopolítico, enquanto o referencial teórico-metodológico elucida as contradições e nos ajuda a olhar com mais profundidade as questões.

A fase de exposição buscou ordenar de forma lógica e coerente a apreensão que se fez da realidade. Tal processo foi sendo reconstituído na pesquisa de campo, sobretudo quando se buscou encontrar, nos depoimentos dos atores entrevistados, a fala-expressão que retratasse a história de uma categoria-classe marcada pelo seu trabalho e delineada por lutas políticas, sociais, culturais e subjetivas. Nesse sentido, esses depoimentos enriqueceram o estudo por serem manifestação viva do processo de institucionalização do trabalhador-sujeito. Cabe ressaltar que os sujeitos entrevistados, em sua participação, têm influenciado o cenário onde a institucionalização do ACS tem transitado. Para identificar cada um deles, criamos quatro categorias que remetem à inserção social do entrevistado no processo de institucionalização: G - gestores; L - Legislativo; M - movimento social, movimento de ACS e movimento popular; $\mathrm{P}$ - pesquisador.

Para apreender o discurso destes atores, que, nos diversos períodos históricos e a partir de diversas formas de representação política contribuíram com a institucionalização do trabalho do ACS e, portanto, são informantes-chave, foram realizadas 14 entrevistas semiestruturadas. Definimos, ainda, que, para cada entrevistado, deveriam ser consideradas suas várias 
inserções sociais e políticas, sendo possível enquadrá-los em mais de uma forma de representação política, conforme a seguinte notação: Gl - representante de gestor - contexto municipal e nacional; G2 - gestor federal e estadual; M1 - ACS e movimento popular; ACS; G3 - gestor federal; G4 gestor estadual; MG5 - movimento popular, trabalhador, gestor, político; M2 - movimento popular e ACS, movimento da categoria; G6 - gestor e pesquisador; G7 - gestor federal e municipal; MG3 - movimento popular, trabalhador, gestor municipal, político e pesquisador; PG8 - pesquisador, gestor federal, municipal e estadual; L4 - advogado, político; M4 - ACS, movimento sindical; G14 - gestor estadual e municipal.

A observação e a análise do trabalho do ACS tiveram como espaço de contextualização o município do Recife, no estado de Pernambuco. Este é um cenário que historicamente tem sido palco de importantes lutas políticas e de articulação de sujeitos implicados tanto na cena local, como no contexto nacional, que foram significativos para a institucionalização do ACS. Entrevistamos, por isso, tanto atores do cenário local (oito entrevistas) quanto do nacional (seis entrevistas).

Depois de transcritas as entrevistas, houve a estruturação do texto, 4 seguida da organização do discurso ${ }^{5}$ e da caracterização da formação discursiva, ${ }^{6}$ que identificou categorias a serem trabalhadas.

Este artigo, por ser parte de uma dissertação de mestrado, não teve a pretensão de abarcar todo o conteúdo apreendido nas entrevistas, mas o relato de todos os atores, de alguma forma, tornou-se parte do nosso discurso interpretativo. A sistematização nos permitiu visualizar o leque de interlocutores e, a partir daí, desenvolver o diálogo entre as partes e organizar as diversas concepções em relação às categorias: Estado, instituição e prática profissional, que serão apresentadas a seguir.

\section{Categorias analíticas: a lente de investigação}

Tendo como referência as categorias mencionadas, cabe aqui um posicionamento quanto à sua análise. Para tanto, é fundamental ponderar sobre a concepção de Estado e instituição nas formações sociais capitalistas, uma vez que tais conceitos podem determinar as concepções e práxis dos atores sociais e da própria sociedade. Para Serra,

A partir da formação do Estado Moderno, no século XVI, configuram-se três principais concepções de Estado, vigentes até o momento atual: a concepção liberal do Estado de Bem-Estar, que atinge seu ápice nos séculos XVII e XVIII; a concepção clássica dos marxismos, surgida com Marx e Engels e depois prosseguida por Lênin, nos séculos XIX e XX, e, por último, a concepção também marxista do 
Estado Ampliado, cuja figura principal é Gramsci, no início do século XX (Serra, 1986, p. 21).

Foi no sentido de aprofundar os elementos que dão significado à produção da prática social do ACS que utilizamos os referenciais propostos por Serra (1986) para compreender a organização do trabalho (Quadro 1), através das categorias Estado, instituição e prática profissional institucionalizada.

Quadro 1

Análise da produção social do trabalho

\begin{tabular}{|c|c|c|c|}
\hline \multirow[t]{2}{*}{ Categoria } & \multicolumn{3}{|c|}{ Concepção } \\
\hline & $1^{a}$ & $2^{a}$ & $3^{a}$ \\
\hline Estado & Acima das classes & Comitê de classe & Espaço contraditório \\
\hline Instituição & Aparelho funcional & $\begin{array}{l}\text { Aparelho de reprodução } \\
\text { da força de trabalho e } \\
\text { das relações sociais }\end{array}$ & Aparelho contraditório \\
\hline $\begin{array}{l}\text { Prática profissional } \\
\text { institucionalizada }\end{array}$ & Articulada à sociedade & $\begin{array}{l}\text { Articulada à classe } \\
\text { dominante com } \\
\text { proposta de prática } \\
\text { alternativa fora do } \\
\text { aparelho institucional }\end{array}$ & $\begin{array}{l}\text { Articulada aos } \\
\text { movimentos populares }\end{array}$ \\
\hline
\end{tabular}

Fonte: Adaptado de Serra (1986, p. 49)

A primeira definição de Estado parte da concepção de Estado de bemestar social, que, na análise de Serra (1986, p. 21), é “amparada nos valores básicos do liberalismo que concebe o Estado como um árbitro que atua acima dos conflitos". A expressão direta dos postulados defendidos pelo Estado de bem-estar se dá por meio das políticas sociais. A primeira concepção de instituição, nessa perspectiva, baseia-se na teoria estrutural funcional de Lourau (1975), em cujo cerne estão as posições teóricas de Weber e Parsons, que têm como ponto central o estudo de categorias ligadas ao poder, tais como autoridade, dominação e legitimidade.

A segunda concepção de Estado é a defendida por Marx e Engels e, depois, por Lênin. Para eles, o surgimento do Estado é decorrência do crescente antagonismo entre as classes, fazendo-se necessário, então, criar "uma força que se colocasse aparentemente acima da sociedade com o fim de atenuar o conflito nos limites da ordem" (Serra, 1986, p. 22). Essa força é o Estado. 
A segunda concepção de instituição fundamenta-se na corrente marxista defendida por Louis Althusser (1970), baseada na visão histórico-estrutural. Para ele, as instituições têm a função de garantir a reprodução das relações sociais e das práticas de dominação, e que "são os Aparelhos Ideológicos que, de fato, asseguram, em grande parte, a própria reprodução das relações de produção, 'escudadas' no Aparelho Repressivo de Estado" (Althusser, 1970, p. 42).

A terceira compreensão de Estado é estruturada por Antonio Gramsci (Buci-Glucksmann, 1970), que propõe uma nova concepção teórica de Estado e de suas conexões com a sociedade civil. Para este autor, o Estado não pode ser visto como um mero reflexo da classe dominante, embora defenda seus interesses. O Estado, dependendo da correlação de forças na sociedade, pode incorporar interesses da classe dominada, contanto que tais interesses não as modifiquem de forma radical.

Chegamos à terceira definição de instituição, que nos é apresentada por Gramsci. Este autor entende instituição como aparelho de hegemonia, influenciado pelo movimento histórico da sociedade e permeado por suas contradições e conflitos. Com base em Madel Luz (1981), conceituamos neste estudo hegemonia como o

processo que o bloco do poder aciona e organiza constantemente no sentido de universalizar seu poder. Definimos hegemonia como processo para sublinhar seu caráter histórico, sempre incompleto, refeito, recomeçado. Na medida em que o Poder é domínio de um lado, condução de outro, sujeição de dominados, liderança de aliados, a hegemonia será contraditória. Lutará contra dissenções de grupos e trações afiadas, combaterá oposições e reações dos grupos subordinados. Neste processo, que inclui mesmo a concessão como tática de luta, a hegemonia de uma classe se modifica constantemente (Luz, 1981, p. 42).

A terceira categoria deste trabalho é a prática profissional institucionalizada, que Serra (1986, p. 16.) organiza em três concepções: a primeira vê a instituição de forma acrítica, e a sua prática profissional produz reações conformistas e ligadas ao poder vigente; a segunda entende que a instituição está a serviço da ordem dominante, vinculada ao sistema de poder, o que implica realizar práticas transformadoras fora do aparelho institucional e, muitas vezes, com caráter político-partidário; por fim, a terceira concepção vê a instituição como espaço contraditório, passível de disputa e de alteração a partir da sua prática profissional. 


\section{Resultados e análises}

\section{O Estado e a instituição}

Ao analisar os discursos dos 14 entrevistados, embora suas inserções fossem diversas, não somente em papéis, mas também na matriz política, não foi possível enquadrá-los na primeira ou na segunda concepção de Estado - a do Estado acima das classes e a do Estado como comitê de classes, respectivamente. Alguns não tocaram no assunto, e os demais deixaram explícita a importância da luta política para modificar as diretrizes do Estado, assumindo, assim, a defesa da terceira concepção de Estado, a do Estado ampliado.

O Estado tem que saber, minimamente, qual é o grau de tolerância que ele tem com as injustiças que ocorrem até hoje. Se a gente não prestar atenção e não disser "não dá para tolerar mais!", eu vou dizer para o governo o que é que ele precisa fazer porque a minha comunidade disse o que era necessário. Se eu não me fizer sujeito dessa ação, o que estamos fazendo é de certa forma uma cooptação, uma acomodação, um ajeitamento dessa sociedade, para que, entre aspas, "a paz reine", e as contradições não apareçam (G6).

No Brasil, as questões referentes às políticas de saúde tomaram proporções importantes no período da redemocratização e trouxeram como pressuposto o chamado 'resgate da dívida social' legada pelo regime militar. Neste estudo, reconhecemos a importância da luta política no setor saúde e acreditamos que o enfrentamento dos problemas e o acúmulo político em relação à agenda impulsionaram a formulação de políticas públicas, no caso, o SUS, e a própria inserção do ACS, como anunciou a VIII Conferência Nacional de Saúde, que defendeu a “(...) incorporação dos agentes populares de saúde como pessoal remunerado, sob a coordenação do nível local do Sistema Único de Saúde, para trabalhar em educação para a saúde e cuidados primários" (Brasil, 1986, p. 12).

A perspectiva de inserir o agente de saúde, como defendeu a VIII Conferência de Saúde, pertence à terceira concepção de um Estado atravessado pelas correlações de força. Neste sentido Estado é, segundo Faleiros (2000, p. 46), “ao mesmo tempo, lugar do poder político, um aparelho coercitivo e de integração, uma organização burocrática, uma instância de mediação para práxis social". O primeiro depoimento a seguir mostra a articulação da comunidade no período da ditadura militar. O segundo depoimento mostra um projeto de cunho popular que, nos anos 1990, torna-se um programa de governo. 
Esse movimento [da comunidade], evidentemente, tinha um caráter político, de resistência, e foi exatamente através desse movimento que criamos condições para voltar a colocar na ordem do dia as lutas do dia-a-dia do povo, de suas necessidades concretas e, portanto, através dessas lutas, ir fazendo também a resistência contra a ditadura (MG5).

O Movimento Popular de Pernambuco se apresenta, na VIII Conferência Nacional de Saúde, com reivindicações como a regulamentação do trabalho do ACS. A gente fez um documento no qual solicitávamos do governo federal que o Estado assumisse aquele trabalho que a gente, até então, fazia dentro da comunidade (M2).

Faz-se necessário resgatar que essa prática se desenvolve em vários lugares do país. No Recife, ela se inicia em meados de 1966, por ocasião de uma grande enchente no município. Um dos entrevistados relata que tal desastre levou a uma comoção pública e foi um momento importante de mobilização e de aproximação de alguns atores sociais com a comunidade dos Coelhos.

A grande cheia de 1966 foi a primeira de impacto, numa época em que não havia nenhuma organização de defesa civil na cidade, e a informação que chegava através da emissora de rádio era que havia essa cheia do rio Capibaribe. E, nesse dia, nós nos juntamos aos moradores e, pela primeira vez, eu vivenciei na prática o conhecimento real do que é uma comunidade rigorosamente excluída e marginalizada (MG5).

Os moradores dos Coelhos ficaram abrigados na paróquia do bairro, espaço já utilizado pelas entidades para realizar reuniões, e, nesse contexto, foi organizada a comissão central do bairro dos Coelhos. Quando a população retornou às suas casas após a enchente, iniciou-se o processo de reconstrução e limpeza das casas, e decidiu-se manter o grupo que estava discutindo as questões de adoecimento.

Esse espaço inicialmente é visto pelos militares como um espaço de discutir a saúde enquanto melhoria da qualidade de vida, e não enquanto um modelo capaz de levar à transformação também da sociedade. Eles viam mais como um modelo que se adaptava ao Estado. Para nós, que estávamos no movimento, víamos um espaço de usar nossas ferramentas em saúde, fazer o diálogo sobre o conceito de saúde, e discutir contrapontos: conceito biológico com o conceito ampliado de saúde. E aí havia um espaço para nós que, de uma forma muito estratégica, nos inserimos no debate político (MG3).

A alternativa utilizada pelo conjunto de sujeitos e movimentos para manter a organização e a luta, no período da repressão, encontrou no setor 
saúde um lócus estratégico. “Então, primeiro, depois de bem discutir cada doença dessas, e a arma para prevenir [cada doença], nós discutíamos por que aquela ação não estava acontecendo no bairro (MG5)". É nessa perspectiva que se consolidam e se ampliam os grupos da saúde, que, anos depois, conseguem uma articulação nacional, capitalizada pelo movimento de reforma sanitária, e criam um arcabouço na defesa de políticas de proteção social.

Alguns fatores interferiram nos rumos da implantação do SUS, um deles foi a desarticulação dos movimentos sociais ligados à saúde, com uma desmobilização dos movimentos populares, dentre eles o Movimento Popular de Saúde (Mops). Albuquerque (2003) tenta explicar esse momento e levanta a hipótese de que o Mops se enfraqueceu com a institucionalização das suas ações via Pacs, com o recrutamento dos seus militantes pelos espaços institucionais, e, além disso, com a entrada destes em outros espaços públicos devido à redemocratização do país.

Quando analisamos os depoimentos dos entrevistados em relação à categoria instituição, percebemos que as três concepções estão presentes, havendo uma concentração na terceira. O relato abaixo demonstrará o Estado como aparelho funcional, na perspectiva do seu dirigente, o ministro. Já o Mops e a Unicef viam o Estado como espaço contraditório, passível de alterações no processo institucional.

Alcenir Guerra chegou à reunião, apresentou o projeto e foi embora. E disse: “Olhem, eu vou fazer o projeto, independente que vocês queiram ou não. É uma decisão do ministro, e o ministro vai fazer". A gente [Mops e Unicef] ficou de decidir. E agora o que é que a gente faz? Bom, o melhor é a gente entrar (M2).

A entrevistada M2 lembra que o ministro Alcenir Guerra, em 1991, chamou o Mops e o Fundo das Nações Unidas para a Infância (Unicef) para uma reunião em que mostrou e defendeu o projeto entregue pelo Mops ao então presidente José Sarney, na VIII Conferência Nacional de Saúde, com significativas alterações, principalmente quanto ao recrutamento dos ACS. Naquela ocasião, o ministro se comprometeu a implantá-lo em todo o país. Para M2, o objetivo dele era tentar melhorar a popularidade do então presidente Fernando Collor. O início da institucionalização do trabalho do ACS ocorre, assim, por meio de importantes negociações realizadas pelo Mops, Unicef e governo federal e se complexifica historicamente com os novos desafios.

Já o relato de PG8 enfatiza a segunda concepção de instituição, defendendo que as mudanças ocorrem somente de fora para dentro. Ao discorrer sobre o desenvolvimento das funções do ACS na comunidade e sua vinculação institucional ao se tornar servidor público, põe em contradição o seu papel de mobilizar, pois esta atividade deveria ser realizada apenas fora do seu horário de trabalho. 
Eu acho que ele deixa de ser comunitário, e ele passa a ser um profissional de saúde. Acho que efetivamente ele pode manter um lado comunitário como cidadão, como eu estou fazendo o meu trabalho do projeto de extensão, na vida política. Mas eu vejo, pela concepção de Estado que eu tenho, que não cabe ao Estado estar fazendo o papel de organização comunitária. Então, não pode mais caber ao ACS organizar uma associação de moradores, um movimento de bairro, uma luta pela posse da terra, pela água, na função de ACS. Ele pode até fazer isso, se ele como cidadão entender que pode. Agora, o Estado também não pode cobrar esse papel dele, porque para mim é contraditório com o papel do Estado (PG8).

Em relação a esse conflito, alguns gestores defendem que não seria necessário que os ACS se tornassem funcionários públicos, uma vez que, para eles, a garantia dos direitos trabalhistas não condiciona o ACS a ser servidor público sob gestão direta. Entretanto, para um dos entrevistados (M4), representante da categoria, ser funcionário público “é um trabalho como outro qualquer, a única diferença é que eu vou ter estabilidade no meu emprego, mais segurança no trabalho". O depoimento de G2 contradiz essa posição, pondo em discussão o papel, as atribuições e a própria essência do elo comunitário.

Eu não necessariamente tinha que transformar os agentes em funcionários públicos. Eu não partilho dessa ideia. Eu estou convencido do contrário. Não sou contra funcionário público, mas considerando que o que faz o agente é diferente de qualquer outro tipo de atividade feita na ordem pública, e que ele nem é Estado completamente, nem é completamente comunidade, ele transita nessas duas dimensões. A situação de ser só Estado burocratiza o trabalho do agente. O agente deixa de ter como referência fundamental sua comunidade, e sim como referência seu chefe (G2).

No início o recrutamento do ACS era feito a partir de suas referências comunitárias e do reconhecimento do seu papel de liderança, tendo como importante função a mobilização popular. As modificações nos processos de recrutamento e seleção têm causado importantes mudanças na relação da instituição com esse trabalhador no que diz respeito às atribuições.

O papel de mediador realizado pelo ACS, fortalecendo as reivindicações populares, tem sido observado por representantes da gestão. As tensões são inerentes a tal papel. Ao fazer interlocução com a comunidade, como parte do serviço, o ACS é visto como braço do governo na comunidade, ora em atitude de solidariedade, ora como facilitador da cidadania. Quando ocorre o inverso, ou seja, quando o ACS representa a comunidade em seu serviço, há também muitos conflitos: ora ele é um articulador dos problemas e soluções, ora é visto como tensionador das reivindicações populares. 
De qualquer maneira, as atribuições dos agentes constroem-se fundamentalmente com base na política pública de saúde, por meio da qual são definidas as necessidades de atenção, as situações de risco e as atividades educativas; portanto, os agentes comunitários de saúde não podem ser entendidos como trabalhadores desvinculados das políticas sociais do Estado - o que não os descompromete da população pela qual são responsáveis. A diferença reside no fato de que o ACS não é mais, como quando ainda era denominado agente de saúde, um braço do movimento popular na luta pela garantia do direito à saúde. Embora com atribuições semelhantes, ele passa a ter uma nova inserção no campo da saúde, com base na qual a sua atuação se desloca, com efeitos interessantes no que diz respeito à possibilidade de maior dedicação e envolvimento, mas que transforma seu vínculo com a população e, de certa maneira, redireciona a sua prática (Lopes, Durão e Carvalho, 2011, p.176-177).

A terceira compreensão de instituição tem como alicerce o Estado ampliado, e é identificada como 'aparelho de hegemonia'. Segundo Luz (1981, p. 30), as instituições são "um conjunto articulado de saberes (ideologia) e práticas (formas de intervenção normalizadora na vida dos diferentes grupos e classes sociais)" e exercem função repressiva quando ligadas à sociedade política, e persuasiva ou educativa (injunções ideológicas junto às camadas populares) quando estão ligadas à sociedade civil. Lopes, Durão e Carvalho (2011) ponderarem que os critérios de contratação e vínculo, bem como o saber ofertado para 'qualificar' a prática do ACS, têm intensificado e produzido novas formas de exploração do trabalho nas classes subalternas.

Ao requerer uma formação escolar mínima e promover formas de contratação absolutamente precárias para esses profissionais, o desenho das novas ações de saúde propostas pelo Ministério da Saúde situa previamente os ACS num espaço social pouco reconhecido, oferecendo-lhes escasso ou nenhum espaço de atuação fora dos limites demarcados pelo alicerce tradicional das práticas em saúde: o saber biomédico. Nessa lógica, não cabe uma maior reflexão sobre a realidade em que os ACS e os usuários estão inseridos, e se repete uma série de condutas que acabam fomentando novos discursos de apassivamento do sujeito e acirrando "novas" formas de exploração (p. 203).

Apesar de as questões apresentadas provocarem os processos de institucionalização do trabalho, para Giffin e Shiraiwa (1989) o trabalhador não é absorvido pela instituição por ser vinculado a ela. Acreditamos que o Estado e a instituição influenciam o trabalho, mas não o determinam, e que a luta social, a partir do trabalho, vinculado ou não ao Estado, imprime processos de contra-hegemonia. 
Além das questões já mencionadas, outras também repercutiram direta e indiretamente no processo de vinculação do ACS, como a busca de um processo de recrutamento/seleção que não perdesse a referência e o vínculo comunitário. Nesse contexto, foi discutido quem era o empregador e quem determinava quem seriam os agentes. Sobre tais questionamentos, G3 explicou que "no passado, quem denominaria, designaria esse profissional de saúde, esse agente de saúde, seria a comunidade". Atualmente, o processo seletivo público é que dá legitimidade e reconhecimento aos vínculos.

Concordamos com Lopes, Durão e Carvalho (2011) sobre ser essencial o pertencimento à comunidade para a constituição da identidade profissional desse trabalhador, e que o recrutamento deva ter como base o local de moradia. Mas defendemos a necessidade de superar esta polêmica que tem restringido o pleno direito de mudança de endereço. Acreditamos que seja fundamental estruturar, através da gestão do trabalho, no plano de carreira deste trabalhador, mecanismos que considerem este problema.

Outro marcador importante é a lei n. 11.350, de 5 de outubro de 2006, que trata do processo seletivo e do vínculo institucional do ACS e apresenta como proposta inicial a contratação direta. Entidades representativas dos gestores públicos e seus contratantes discordaram do encaminhamento definido pela lei e tentaram mediar a questão, como o fez, segundo L4, o Conselho Nacional de Secretarias Municipais de Saúde (Conasems). Tal aspecto permanece em disputa no conjunto dos municípios, já que a contratação continua ocorrendo de forma diversa e precarizada.

Segundo G1, o Conasems defendeu que o vínculo do ACS não fosse direto e propôs a continuidade das formas de contratação anteriormente pactuadas. Diante dessa divergência, a estratégia de contratação indireta foi mantida pelos atuais governos dos municípios. Trata-se da celebração de termos e contratos de parcerias com Organizações Sociais de Saúde (OSS), Organizações da Sociedade Civil de Interesse Público (Oscip) e cooperativas. Para isso, os gestores defendem a manutenção da intermediação na contratação.

A assessoria jurídica do Conasems trabalha um pouco essa questão de diferenciação entre o que é parceria e o que é terceirização. Terceirização é uma coisa muito diferente de parceria, é quando você contrata uma determinada empresa, faz um contrato com uma ONG, Oscip ou com uma fundação para que ela contrate a força de trabalho em saúde (...). Parceria, por outro lado, significa o município, o gestor municipal, ou o gestor estadual, enfim, estabelecer uma parceria com uma ONG, uma Oscip, ou uma fundação, estabelecendo uma parceria com base num projeto de gestão com metas, resultados, com controle social, porque você faz a parceria com base no SUS (Gl). 
O relato discorre sobre a tentativa de diferenciar questões que são indissociáveis em seu cerne, uma vez que parceria e terceirização são formas de transferir responsabilidades públicas para entes da iniciativa privada. Por isso é fundamental analisar o impacto dessa forma de gestão no sistema ocupacional e nas relações de trabalho. Esta reengenharia no processo de organização, gestão e contratação da força de trabalho pode estar atendendo prioritariamente às demandas e necessidades dos contratantes de serviços, já que parecem seguir a ordem do mercado. Segundo Cherchglia, a terceirização é

uma forma especial de privatização onde organizações públicas, sob a égide de provisão pública, realizam a transferência contratual e parcial da responsabilidade pela produção de alguns de seus serviços a empresas privadas. No entanto, a Administração Pública está adstrita ao princípio da legalidade (art. 37 da Constituição), só podendo fazer aquilo que a lei determina e não aquilo que a lei não proíbe. Assim, as formas de terceirização na Administração Pública deverão estar respaldadas na lei, sob pena de ilegalidade do ato e responsabilidade do servidor que o praticou (Cherchglia, 1999, p. 370).

As mesas de negociação dos trabalhadores têm posto em sua agenda prioritária questões relacionadas não somente ao vínculo e à desprecarização do trabalho do ACS, mas também à organização e à qualificação do trabalho. O setor saúde não está à margem das transformações do mundo do trabalho. As pressões advindas do aumento dos investimentos na saúde têm propiciado um campo fértil para a terceirização no setor.

O entrevistado G6 manifesta sua preocupação quanto à modificação desse trabalhador a partir do novo processo de vinculação: “O que será daqui a dez anos desses ACS? Há riscos de desconfiguração da função social do agente comunitário?". Ele aponta a perda de três grandes valores: o vínculo, a legitimidade e a confiabilidade, mas, de forma contraditória, mantém o otimismo e aposta que:

Se ele cada vez mais se afastar da intenção política, social e, até, digo, ideológica, do que é o ACS, de ser um educador para a saúde, de ser um sujeito de certa forma privilegiado na comunidade, que amplia o seu diálogo para além do seu escopo comunitário, dando aporte ao serviço, e começar a apreender outros conhecimentos, e fazer essa troca do saber popular e do saber científico, e se reconstrói e se recodifica com seu novo mundo, se ele faz isso, ele vai prestar um grande serviço à nação brasileira, porque a finalidade é que ele seja esse educador em saúde, com a ideia principal de que as pessoas possam cuidar da sua saúde, tenham conhecimento disso, tenham capacidade reivindicatória, saibam se posicionar perante o Estado (G6). 
Pensar a integralidade no SUS é considerar no seu arranjo saberes e práticas populares, e, para isso, é fundamental reavivar a luta política desses trabalhadores, bem como dos diversos atores que concordam com a defesa de um projeto popular para a saúde. O desafio, hoje, é manter a resistência e buscar mecanismos que não alienem o trabalhador. É preciso que o desenvolvimento do seu trabalho seja a produção de uma luta política contra a ordem social opressora, em defesa do SUS, da vida, e de uma sociedade socialmente justa.

Seguiremos discorrendo sobre os elementos que permeiam a terceira concepção da prática profissional institucionalizada, com o objetivo de provocar reflexões críticas e tecer alternativas que busquem superar a hegemonia no campo da educação, da saúde e do trabalho, que perpassam a institucionalidade do ACS.

As três perspectivas de prática profissional aparecem nos discursos dos entrevistados, embora, para a maioria, o ACS seja um sujeito crítico e produtor de novas ordens e de resistência popular, como defende MG5: "Agente de transformação incomoda, e incomoda, inclusive, à gestão, porque eles não estão ali para pedir acomodações, mas sim para colocar em movimento a população, para fazer transformações de impacto na saúde".

Segundo Luz (1981) a prática institucional tende a ser conflituosa (vista do ângulo das relações sociais) e contraditória (vista do ângulo da estrutura). No depoimento a seguir, evidenciam-se divergências quanto à realização de algumas funções que não são atribuições do ACS.

A gente tem que tirar prontuário, organizar entrada e saída de pacientes, entregar a medicação, desmembrar exames. A doutora solicita os exames e a gente tem que marcar, desmembrar naqueles papéis que vêm do laboratório. E ainda nas quartasfeiras, às sete horas da manhã, a gente faz um rodízio para ajudar a auxiliar de enfermagem na coleta, porque a gente acha que é muita coisa para ela fazer sozinha. Então, são muitas coisas que a gente acumula, mas que não são nossas funções (M1).

As novas atribuições e os problemas administrativos e de gestão, como por exemplo, a insuficiência de trabalhadores nas unidades para desempenhar atividades que são fundamentais para o seu funcionamento, são algumas das barreiras que acabam produzindo desvios de função e aprisionamento do ACS na unidade de saúde. Para Morosini, Corbo e Guimarães (2007, p. 267), o desvio de função se dá pela “compreensão do trabalho do ACS como inespecífico e de baixa complexidade, podendo ser redirecionado, segundo as necessidades dos serviços, para atividades que supostamente exigem pouca capacitação".

Enfrentar as questões referentes ao desvio de funções do ACS deve ser pauta da gestão pública e reivindicação desses trabalhadores. Tal situação 
tem criado tensões relacionadas à organização do trabalho e à estrutura do serviço, mantida pelas relações de poder e pelas regras institucionais e sua hierarquia.

A abordagem feita por Luz baseada em Gramsci introduz temas relativos à hegemonia e à conjuntura social e, portanto, à ligação das instituições na sociedade política e civil. A autora procura aproximar Gramsci e Foucault, apoiando-se no segundo quando destaca a relevância de se compreender o discurso institucional (saberes) e sua relação com o poder, isto é, a relação poder/saber institucional. Ao ser incluído em uma política, o trabalho do ACS sujeita-se a alguns rearranjos, transformando o seu discurso em discurso institucional.

A prática social do ACS tem no seu surgimento a conexão entre 'poder' e 'saber' atrelada à construção popular. Ao serem institucionalizadas, essas duas noções vão se modificando. A inserção pública, a criação da profissão do ACS e a regulamentação do trabalho reconfiguram suas funções, papéis e atribuições. Segundo o entrevistado G3, isso desvirtua, distorce o que seriam o papel, a função e o perfil do ACS. O saber sofre influência de concepções tecnicistas de saúde e o poder passa a ser matéria de disputa.

Depois, com o PSF [Programa Saúde da Família], a função de mediador passa a ser a função de transmissor de recado. Ele passa a ser muito mais a ponte exclusivamente da informação da assistência - ele marca a consulta e traz a informação do dia e hora marcados. Veem os exames necessários, ele marca e traz a informação de quais foram marcados, do transporte, do Bolsa Família etc. Então, aí, ele perde o caráter comunicativo da sua função, a coisa de estar conquistando aquela população para um processo de formação da saúde é bem menor (PG8).

Embora o ACS não concorde com as 'normas' institucionais condicionadas pela estrutura precária do serviço mencionada no depoimento anterior, as normas impostas criam certo constrangimento entre trabalhadores/equipe/comunidade, forçando o ACS a fazer mediações e concessões. Isso demonstra que esse é um processo conflituoso, tanto na micro quanto na macropolítica.

A gente fez uma revolução e deixou de marcar consulta. "Se quiser, você vai ter que ir lá no posto marcar". E foi aí que a gente começou a se voltar mais para os grupos, para as reuniões, para os encontros. E tudo o que a gente faz tem uma razão, porque a nossa ideia é transformar as pessoas, politicamente, para que elas possam lutar por seus direitos (M1).

Novas atribuições têm afastado o ACS de práticas que traduzem o seu saber/fazer comunitário. As novas competências a serem desenvolvidas por 
este trabalhador têm disputado lugar/tempo com as ações que contribuem para a organização da comunidade.

Eles são agentes públicos para as questões que lhes cabem nas atividades comunitárias de saúde, mas são cidadãos conscientes e que na sua comunidade lutam por direitos. Eu acho que esse momento [de desprecarização do vínculo] vai fazer a grande diferença, poderá ser o grande salto. Por exemplo, a conquista política de sua efetivação, a clareza de procedimentos para sua seleção, a consciência do que é ser servidor público sem deixar de ser cidadão. E, como uma das características, você ser um cidadão engajado na luta do povo. Poderá ser agora o grande momento de reflexão dos agentes comunitários de saúde (MG5).

A tentativa de moldar a prática do ACS tem avançado junto às conquistas da regulamentação e de sua ampliação. Outro componente que se tem modificado é o recrutamento, que não vincula mais o perfil do ACS à representação comunitária, apenas ao lugar de moradia. Embora o fato de viver na comunidade não garanta o seu comprometimento com ela, a manutenção no contexto comunitário pode despertá-lo para um possível envolvimento comunitário.

Segundo Luz (1981), é através das relações que aceitamos complexas hierarquias sociais. Deste modo se fixam e se reproduzem as relações sociais e o poder do próprio sistema capitalista. As regras que fundamentam as relações institucionais são a ordem e a disciplina. A ordem garante a estrutura, e a disciplina assegura as relações sociais. Elas são interdependentes. "É necessário estabelecer a ordem para manter a disciplina e assegurar a disciplina para que não haja quebra de ordem" (Luz, 1981, p. 36). A base de apoio do triedro do poder institucional é a hierarquia.

Luz (1981, p. 39) afirma ainda que “ordem, disciplina e hierarquia são os valores do campo de forças que definem o triedro institucional. Neste campo de forças, a resultante seria o saber". Nas instituições diretamente ligadas ao Estado, o poder é mediado por um saber que se apresenta como um conjunto de técnicas e de regras de conduta, de normas de proceder e de conhecer. Vejamos como isto se configura para o ACS em relação à sua formação técnica.

No que diz respeito à formação, educação continuada, permanente, (...) eu vejo que é uma perda o agente de saúde ser transformado em técnico de saúde e na expressão restrita que um técnico incorpora. Ser agente lembra muito um profissional de transformar, de mudar. E ser técnico parece ser, assim, um comportamento mais estético, no sentido mesmo de arrumar do que no sentido de transformar. E aí, nesse sentido, há perda! (...) Mas esse é o papel que o Estado quer. O Estado não quer um agente transformador, talvez modelador (MG3). 
Embora existam diversos campos de tensões relacionadas à qualificação técnica do ACS, optamos, neste estudo, por explicitar apenas três: a tecnicização da prática de um trabalho com importantes características fundadas no saber popular; a necessidade de organizar processos de desenvolvimento profissional e constituição de carreira; e a fragilidade das instituições formadoras em constituir processos formativos condizentes com 'novas lógicas científicas' (alicerçadas em saberes populares) produtoras de implicação comunitária e de cuidados emancipatórios.

Compreendemos que a formação técnica dos ACS por si só não é garantia de que não se incorra numa formação instrumentalizadora, agora, com o status tecnificado. Para evitar isso, é necessário que essa formação técnica parta do entendimento da educação como um conjunto de práticas sociais que se articulam, baseadas nas ciências, constituindo uma formação que, além de técnica, precisa ser ética e política - no sentido de se aproximar da formação humana (Morosini, Corbo e Guimarães, 2007, p. 272-273).

Na perspectiva de diversificar e modificar a prática de cuidar fez-se uso do recrutamento de um novo sujeito, com saberes diferentes, cujo trabalho, com medidas simples, impactou, por exemplo, nos índices de mortalidade infantil. Após duas décadas de aproximação com este trabalhador, interrogamos: será que não se conseguiu apreender formas de desenvolver conhecimentos e mediar novas práticas mais próximas destes saberes?

O cotidiano dos serviços, marcados pela racionalidade do modelo biomédico, tem influenciado a produção da prática profissional do ACS. Os diversos processos formativos - primeira etapa do curso técnico, introdutório, e as diversas capacitações - têm produzido conhecimentos e práticas tecnicistas e biologicistas.

A (não) escolarização do ACS, justificada pela necessidade de esse trabalhador ser representativo da comunidade em que atua, denota a desvalorização da dimensão conceitual de sua qualificação, o que fortalece a desvalorização social desse trabalhador, sustenta a sua baixa remuneração e contrapõe-se à pauta política por uma melhor qualificação dos trabalhadores da saúde, de uma maneira geral (Morosini, Corbo e Guimarães, 2007, p. 267).

Nesse sentido, retomar e repensar a agenda do curso técnico poderá ser uma aposta estratégica para qualificar o trabalho e desenvolver o saber e o fazer crítico, reflexivo e transformador da realidade. Além de compreender que a formação técnica coloca em questão não somente a transformação do ACS em técnico, mas, de forma estratégica, a organização de uma carreira para este trabalhador. 
No entanto, não se pode esquecer que a formação não só conforma, mas traz a possibilidade de transformação da realidade. Talvez um dos sentidos não manifestos encobertos pelos discursos contra a formação seja o temor de que uma maior conscientização dos agentes os leve a questionar as políticas em curso, pois, mesmo com muitas dificuldades, esses trabalhadores vêm tentando se articular em um movimento mais orgânico, lutando contra uma tendência das políticas públicas de encapsulá-los no local de moradia e no cotidiano do trabalho (Lopes, Durão e Carvalho, 2011, p. 204).

É necessário enfrentar a questão da produção do conhecimento e do seu desenvolvimento como prática na rede básica de saúde, onde a formação tem sido inadequada e insuficiente para todos os trabalhadores, inclusive o ACS. Para isso cabe refletir sobre a falta de preparação dos centros de formação para desenvolver conhecimentos condizentes com as necessidades desse sujeito, bem como para a própria atenção primária. Se as instituições formadoras, alicerçadas em pedagogias críticas, se prepararem para desenvolver mecanismos capazes de integrar saberes e práticas, a formação será um importante dispositivo para potencializar a prática deste trabalhador.

\section{Considerações finais}

Compreendemos que a estruturação da prática profissional ocorrerá na sociedade por meio da correlação de forças e dos consensos socialmente construídos, e consideramos que a prática institucionalizada apresenta limites, mas tensiona as regras e normas que tentam ser hegemônicas. Outro componente vital a ser apreciado na produção/institucionalização da prática profissional é o saber institucional oferecido a este profissional. A sua prática é institucionalizada como atribuição, e reconhecida pela instituição que, portanto, pode ser retirado por ela, caso não se sujeite aos ditames legais para sua utilização. No caso do ACS, a prática é também mediada pelo saber constituído na sua dinâmica popular, como esclarecem Bornstein e Stotz:

A riqueza da atuação do agente comunitário de saúde na mediação de saberes se dá justamente por sua origem e inserção na comunidade onde atua e, ao mesmo tempo, por sua participação profissional no serviço de saúde; isto lhe possibilita o acesso ao saber popular e também ao tecnocientífico (Bornstein e Stotz, 2009, p. 463).

Constatamos que o profissional, em sua prática cotidiana, coloca-se entre as demandas da população e as exigências e determinações da instituição, e que "frequentemente, as carências determinadas pelas instituições como 
sendo da clientela (população) não são as mesmas que essa considera e define" (Serra, 1986, p. 41). A produção da prática profissional do ACS se institucionaliza mediada pelas lutas sociais e políticas. A posição de mediação do agente profissional entre os instituintes e os instituídos não significa que, necessariamente, ele receba delegação de poder dos 'donos' da instituição onde trabalha e que não possa optar por outro encaminhamento.

Este estudo buscou mostrar que as formas de recrutamento iniciadas nas décadas de 1970 e 1980, vinculadas às organizações comunitárias, favoreciam o envolvimento dos ACS nas lutas populares. Para nós, o processo de institucionalização, e com isso a forma de recrutamento dos ACS na atualidade, enfraqueceu seu vínculo com a comunidade. No entanto, o que vimos, tanto na pesquisa de campo como na rotina de trabalho da gestão da rede básica, é que, de forma persistente, esse comprometimento continua existindo. Um dos pressupostos que levantamos é que a produção de vida e de trabalho desse sujeito é cotidianamente atravessada pelos problemas sociais existentes na sua rotina pessoal, social, comunitária e profissional. Com isso, torna-se muito difícil não distinguir tais problemas e não se sentir parte deles.

Compreendemos que a ordem dominante tem modificado o trabalho do ACS e, quando não altera a sua prática, tenta modificá-la através dos desvios de função, como marcação de consulta, recepção, entre outras atividades. Já a manutenção/produção de funções/práticas contra-hegemônicas é respondida com efeitos repressivos. A divergência é vista como desordem - desvio ou contraordem -, subversão. A disputa pela centralidade da prática do trabalhador vem recebendo forte investida institucional, suscitando consideráveis movimentos de resistência tanto por parte da categoria como de seus apoiadores. Há uma significativa defesa das funções de educador e mobilizador como papéis essenciais para esse trabalho e para a continuação da luta por um projeto popular para a saúde.

Assim, considerando as origens e o processo histórico de formação dos ACS, bem como sua vinculação com as classes populares, é de se supor que essa conexão colabore para a evolução da profissão no sentido da incorporação de práticas contra-hegemônicas. Com o acúmulo de saber popular, esse profissional pode ser qualificado como um intelectual orgânico, já que é um potente ator com função organizativa para a peleja contra-hegemônica.

A ação desse novo ACS pode se expressar de diversas formas. O primeiro resultado é que o ACS, por si só, é um agente contraditório para a política institucional, na medida em que pode ser considerado como extensão do poder popular. O segundo efeito é que, ao estar inserido (trabalhar e viver) no território-processo, as consequências da divisão de classe tornam-se parte da sua ocupação e vida, aproximando-o das dimensões que compõem a resistência institucional, ou seja, da tomada de consciência, da organização e da aliança. 
As conquistas e a força movimentada por esses trabalhadores agregam grandes desafios. É fundamental que os ACS saibam o valor político de sua institucionalização: a consciência de ser servidor do povo, do seu papel de trabalhador, de agente da comunidade e do enfrentamento necessário às adaptações promovidas pelo Estado e pelas instituições. É importante que os ACS tomem como estratégica a vanguarda dos processos educativos, tanto para a sua qualificação, como para a interlocução com a população, e também que interfiram nas qualificações propostas, bem como que criem, de forma autônoma, espaços de qualificação da sua práxis e da própria comunidade, alicerçados em saberes populares, produtores de reflexões e práticas críticas, e transformadoras da realidade.

\section{Nota do Editor}

Agleildes Arichele Leal de Queirós fez a revisão bibliográfica, coleta e análise dos dados e a redação do manuscrito. Luci Praciano Lima participou da análise dos dados e da redação do manuscrito.

\section{Colaboradores}

Este artigo é resultado da dissertação de mestrado em Saúde Coletiva, cursado na Universidade Federal de Pernambuco (UFPE), intitulada "A institucionalização do trabalho do Agente Comunitário de Saúde em Recife". Foi realizada pela primeira autora e orientada pela segunda, com financiamento da Coordenação de Aperfeiçoamento de Pessoal de Nível Superior (Capes) por meio de bolsa de mestrado. Recebeu aprovação do Comitê de Ética em Pesquisa do Centro de Ciências da Saúde (CCS), da Universidade Federal de Pernambuco (UFPE). 


\section{Notas}

1 Sanitarista da Secretaria Municipal de Saúde de São Bernardo do Campo, São Paulo, Brasil. Doutoranda em Ciências pela Faculdade de Saúde Pública da Universidade de São Paulo (USP).<liu_leal@yahoo.com.br>

Correspondência: Rua da Consolação, 2.764, apto. 32, CEP 01416-000, Cerqueira César, São Paulo, SP, Brasil.

2 Professora do Departamento de Medicina Social da Universidade Federal de Pernambuco (UFPE), Recife, Pernambuco, Brasil. Doutora em Saúde Coletiva pela Universidade Estadual de Campinas (Unicamp). <lucilima@uol.com.br>

3 Utilizamos Lessa (1999) para compreender melhor o que denominamos 'complexo social' e 'reprodução social'. Complexo social é o conjunto de relações sociais que se distinguem das outras relações pela função social que exercem no processo reprodutivo. Reprodução social é o complexo processo que, fundado pelo trabalho, termina dando origem às relações entre os homens que não mais se limitam ao trabalho como tal, mas dão origem a novas relações.

4 Texto: unidade complexa de significação cuja análise implica as condições de sua produção (contexto histórico-social, situação, interlocutores) (Brandão, 2002, p.110).

5 Discurso: é o efeito de sentido construído no processo de interlocução “aquilo que se diz significa em relação ao que não se diz, ao lugar social do qual se diz, para quem se diz, em relação a outros discursos" (Brandão, 2002, p. 106).

6 Formação discursiva: define-se pela sua relação com a formação ideológica "o que pode e deve ser dito" a partir de um lugar social historicamente determinado (Brandão, 2002, p. 106).

\section{Referências}

ALBUQUERQUE, Paulette Cavalcanti. A educação popular em saúde no município de Recife-PE: em busca da integralidade. Tese (Doutorado em Saúde Pública) - Rio de Janeiro, Escola Nacional de Saúde Pública Sergio Arouca, Fundação Oswaldo Cruz (Ensp/Fiocruz), 2003.

ALTHUSSER, Louis. Ideologia e aparelhos ideológicos do Estado. Tradução de Joaquim José Moura Ramos. Lisboa; São Paulo: Presença; Martins Fontes, 1970.
BORNSTEIN, Vera Joana; STOTZ, Eduardo Navarro. O trabalho dos agentes comunitários de saúde: entre a mediação convencedora e a transformadora. Trabalho, Educação e Saúde, Rio de Janeiro, v. 6, n. 3, p. 457-480, 2009.

BRANDÃO, Maria Helena Nagamine. Introdução à análise do discurso. 2. ed. rev. São Paulo: Ed. Unicamp, 2004.

BRASIL. Ministério da Saúde. Secretaria de Atenção Básica. Planilha de cobertura, 
competência de maio de 2011. Brasília: Ministério da Saúde, 2011.

. Ministério da Saúde. VIII Conferência Nacional de Saúde. Relatório final. Brasília: Ministério da Saúde, 1986. Disponível em: <http://conselho.saude.gov.br/ biblioteca/Relatorios/relatorio_8.pdf > . Acesso em: 5 out. 2011.

BUCI-GLUCKSMANN, Christine. Gramsci y el Estado: hacia una teoria materialista de la filosofia. 3. ed. México: Siglo Veintiuno, 1970.

CHERCHIGLIA, Mariangela Leal. Terceirização do trabalho nos serviços de saúde: alguns aspectos conceituais, legais e pragmáticos. In: SANTANA, José Paranaguá de; CASTRO, Janete Lima de Castro. (Orgs.). Capacitação em desenvolvimento de recursos humanos de saúde: CADRHU. v. 1. Natal: Ed. UFRN, 1999. p. 361-385.

CHINELLI, Filippina; LACERDA, Alda; VIEIRA, Monica. A reconfiguração gerencial do Estado brasileiro e os trabalhadores da saúde nos anos 1990. In: VIEIRA, Monica; DURÃO, Anna Violeta; LOPES, Marcia Raposo (Orgs.). Para além da comunidade: trabalho e qualificação dos agentes comunitários de saúde. Rio de Janeiro: Escola Politécnica de Saúde Joaquim Venâncio, 2011. p. 33-78.

DENZIN, Norma K.; LINCOLN, Yvonna S. (Orgs.). O planejamento da pesquisa qualitativa: teorias e abordagens. 2. ed. Porto Alegre: Artmed Bookman, 2006.

DOIMO, Ana Maria; RODRIGUES, Marta Maria Assumpção. A formulação da nova política de saúde no Brasil em tempos de democratização: entre uma conduta estatista e uma concepção societal da atuação política. Politica \& Sociedade, Florianópolis, v. 3, p. 1-30, out. 2003.

DURÃO, Anna Violeta; MOROSINI, Márcia Valéria; CARVALHO, Valéria. Os agentes comunitários de saúde e o conceito de comunidade na configuração de sua qualificação.
In: VIEIRA, Monica; DURÃO, Anna Violeta; LOPES, Marcia Raposo (Orgs.). Para além da comunidade: trabalho e qualificação dos agentes comunitários de saúde. Rio de Janeiro: Escola Politécnica de Saúde Joaquim Venâncio, 2011. p. 33-78.

FALEIROS, Vicente de Paula. Politica social do Estado capitalista. 8. ed. São Paulo: Cortez, 2000.

FRIGOTTO, Gaudêncio. O enfoque da dialética materialista histórica na pesquisa Educacional. In: FAZENDA, Ivani (Org.). Metodologia da pesquisa educacional. 2. ed. São Paulo: Cortez, 1991.

GADOTTI, Moacir. Pedagogia da práxis. 4. ed. São Paulo: Cortez, 2004.

GIFFIN, Karen; SHIRAIWA, Tizuko. O agente comunitário de saúde pública: a proposta de Manguinhos. Cadernos de Saúde Pública, Rio de Janeiro, v. 5, n. 1, p. 24-44, 1989.

KOSIK, Karel. Dialética do concreto. Rio de Janeiro: Paz e Terra, 1976.

LESSA, Sérgio. O processo de produção/ reprodução social: trabalho e sociabilidade. Capacitação em serviço social e politica social: módulo 2: Brasília: Centro de Educação a Distância (Cead)/UnB, 1999. p. 20-32.

LOPES, Marcia Raposo; DURÃO, Anna Violeta; CARVALHO, Valéria. A disputa sobre os sentidos do trabalho e da formação dos agentes comunitários de saúde. In: VIEIRA, Monica; DURÃO, Anna Violeta; LOPES, Marcia Raposo (Orgs.). Para além da comunidade: trabalho e qualificação dos agentes comunitários de saúde. Rio de Janeiro: Escola Politécnica de Saúde Joaquim Venâncio, 2011. p. 161-207.

LOURAU, René. A análise institucional. 1. ed. Petrópolis: Vozes, 1975.

LUZ, Madel Therezinha. As instituições médicas no Brasil: instituição e estratégia de hegemonia. Rio de Janeiro: Graal, 1981. 
MARX, Karl. O Dezoito Brumário de Luiz Bonaparte. São Paulo: Abril, 1978. (Coleção Os Pensadores).

O capital: crítica da economia política. Livro I, v. 1. 23. ed. Rio de Janeiro: Civilização Brasileira, 2006.

MOROSINI. Márcia Valéria; CORBO, Anamaria D'Andrea; GUIMARÃES, Cátia Corrêa. O agente comunitário de saúde no âmbito das políticas voltadas para a atenção básica: concepções do trabalho e da formação profissional. Trabalho, Educação $e$ Saúde, Rio de Janeiro, v. 5, n. 2, p. 261-280, 2007.

NAKATANI, Paulo. A questão metodológica na discussão sobre a centralidade do trabalho. Análise Econômica, Porto Alegre, v. 19, n. 35, mar. 2001.

PIRES, Denise. Reestruturação produtiva e consequências para o trabalho em saúde. Revista Brasileira de Enfermagem, Brasília, DF, v. 53, p. 251-63, 2000.
QUEIRÓS, Agleildes Arichele Leal. A institucionalização do trabalho do ACS em Recife. Dissertação (Mestrado em Saúde Coletiva) - Recife, Programa Integrado de PósGraduação em Saúde Coletiva, UFPE, 2008.

RODRIGUES, Maísa Paulino; ARAÚJO, Mariza Sandra de Souza. O fazer em saúde: um novo olhar sobre o processo de trabalho na Estratégia Saúde da Família. Natal, 2001. Observatório RH, NESC/UFRN. Disponível em: <www.observatorio.nesc.ufrn.br $>$. Acesso em: 10 set. 2007.

SERRA, Rose Mary Sousa. A prática institucionalizada do serviço social: determinações e possibilidades. 3. ed. São Paulo: Cortez, 1986.

SILVA, Joana Azevedo da; DAMALSO, Ana Sílvia Whitaker. Agente comunitário de saúde: o ser, o saber, o fazer. Rio de Janeiro: Ed. Fiocruz, 2002.

Recebido em 23/11/2010

Aprovado em 15/08/2011 